$70 \mathrm{~mm}$. of air. $X$-ray films showed enormous internal hydrocephalus, but the aqueduct and fourth ventricle could not be filled. Iophendylate $6 \mathrm{ml}$. was injected after releasing the air from the ventricles. Complete occlusion of the aqueduct was demonstrated. Two days later the patient complained of headache and nausea, and there was slight stiffness of the neck. The exophthalmos had increased.

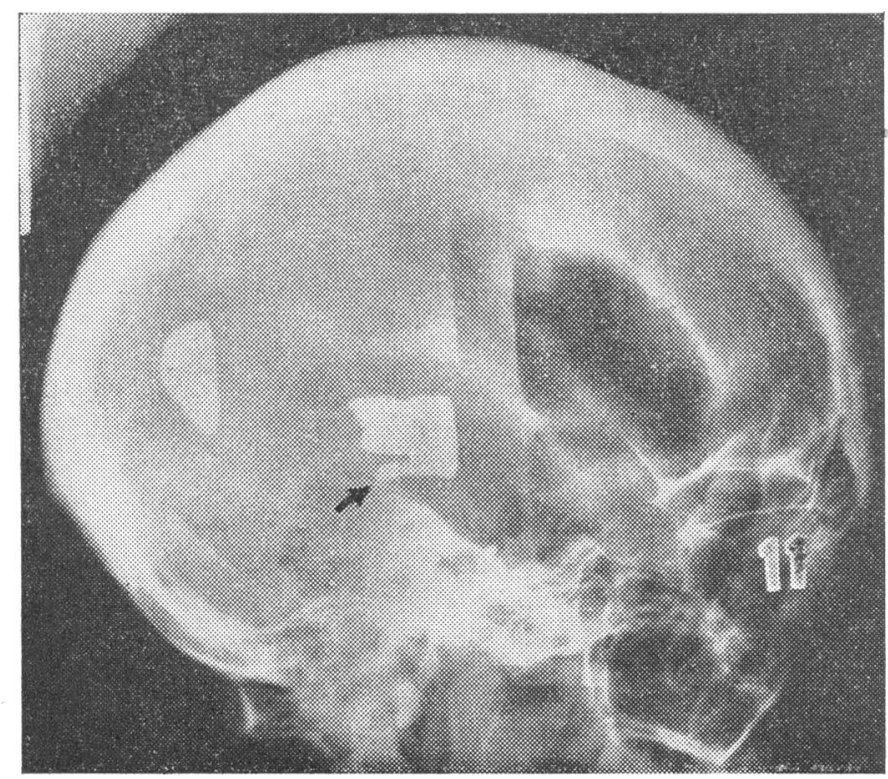

Fig. 3.-Double contrast ventriculogram showing hydrocephalus and complete obstruction to the downward flow of iophendylate through the aqueduct of Sylvius at the point marked with an arrow.

On 3 December an atrioventricular shunt was performed. A Spitz-Holter valve was first tested and found to open at $80 \mathrm{~mm}$. of $\mathrm{H}_{2} \mathrm{O}$ pressure. The valve was then inserted, establishing a connexion between the right lateral cerebral ventricle and the right atrium of the heart.

By the next day exophthalmos had diminished. Within a week she had no complaints apart from slight numbness of the left corner of the upper lip. Papilloedema and exophthalmos were less. By June 1966 there were no signs or symptoms of thyrotoxicosis, and the thyroid was no longer palpable. The $T$ index was measured again in June 1966 and found to be 7.9. The uptake of ${ }^{131} \mathrm{I}$ was $46 \%$ at 24 hours and $44 \%$ at 48 hours. These figures may be unduly low owing to iophendylate.

In July 1967 the Russell Fraser $T$ test gave a figure of 1.32, though there were no symptoms or signs of myxoedema. The uptake

\section{Sensitivity to Propranolol after Digoxin Intoxication}

\section{Brit. med. F., 1968, 4, 413-414}

Cardiac arrhythmias are a well-recognized manifestation of overdosage with glycosides of the digitalis group. These arrhythmias may be relatively benign or of ominous prognosis. Before the introduction of $\beta$-adrenergic blocking agents the treatment of digitalis-induced arrhythmias consisted of withdrawal of the glycoside and administration of potassium. With the advent of propranolol, however, it was found possible to reverse these arrhythmias almost specifically.

$\beta$-Adrenergic blockade is itself not devoid of hazard. In particular, the usually recommended dosage may be poorly tolerated and the undesirable effects of propranolol may be substituted for the arrhythmia being treated. Two such instances are reported. at 24 hours was $7.5 \%$ and at 48 hours $6.9 \%$. The drop in these figures can only be due to diminution in thyroid function in the previous year, for the action of iophendylate would have lessened. The protein-bound iodine could not be determined owing to the previous use of iophendylate. In November 1967 the exophthalmometer reading was $1.9 \mathrm{~cm}$. on each side. In February 1968 the protein-bound iodine was still contaminated by iophendylate. The serum thyroxine iodine measured $6.7 \mu \mathrm{g} . / 100 \mathrm{ml}$. (normal 3.5 to 7.5), the free thyroxine index was 5.5 (normal 3.1 to 7.7 ), and the $\mathrm{T}_{3}$ resin uptake $83 \%$ (normal 90 to $110 \%$ ). These tests, which are not vitiated by iophendylate, show a return towards normal thyroid function. The patient has remained well since, with no signs or symptoms of intracranial pressure or thyrotoxicosis. The upper lid retraction has disappeared. The goitre is no longer palpable.

\section{Discussion}

The interest in this case, which appears to be unique, rests in the fact that the patient had two possible causes for exophthalmos-stenosis of the aqueduct and thyrotoxicosis. In view of the rapid recovery from exophthalmos after operation it seems probable that it was due to the former cause.

The concomitant development of thyrotoxicosis and its remission after drainage of the aqueduct is harder to explain. We were tempted at first to suspect that abnormal pressure within the hypothalamus had produced an increase in thyroidstimulating hormone-releasing substance, but Professor Munro failed to find either thyroid-stimulating hormone or long-acting thyroid stimulator in the patient's serum.

The possibility cannot be dismissed that the thyrotoxicosis was coincidental and its disappearance spontaneous, but this seems unlikely in the circumstances described.

We are grateful to Mr. Anthony Green, of the Royal Northern Hospital, and to Miss Helen Farran, of New End Hospital, for carrying out the isotopic tests, and to Professor D. S. Munro for his attempt to demonstrate thyroid-stimulating hormone and longacting thyroid stimulator.

RAYMOND GREENE, M.A., D.M., F.R.C.P., Honorary Consultant Physician, Royal Northern and New End Hospitals, London.

LESLIE C. OLIVER, M.B., F.R.C.S., F.A.C.S., Consultant Neurological Surgeon, Charing Cross and Royal Northern Hospitals, and the West End Hospital for Neurology and Neurosurgery, London.

\section{CASE Reports}

Case 1.-A 45-year-old man had rheumatic aortic stenosis and regurgitation. He had been treated at home with bendrofluazide and digoxin for cardiac failure, and the electrocardiogram (E.C.G.) showed atrial fibrillation, frequent ventricular extrasystoles, and ST-T changes consistent with digoxin administration. The degree of irritability was thought severe enough to warrant intervention, and a single oral dose of propranolol $(10 \mathrm{mg}$.) was given with apparently satisfactory effect. The ventricular irritability was abolished and the rate fell. Two hours later the rate was $64 / \mathrm{min}$. After six hours it had fallen to $44 / \mathrm{min}$. Unfortunately, the drug had only recently been introduced, and information about recognition and treatment of overdosage was not available. Shortly after treatment he collapsed. The E.C.G. showed asystole, and attempts at resuscitation failed, Necropsy confirmed aortic and mitral valve disease and left ventricular hypertrophy. The myocardium and coronary arteries were healthy. There was no cardiac failure.

Case 2.-A previously fit man of 72 was admitted to hospital with chest pain of eight hours' duration, dyspnoea, and tachycardia. Before admission he had been given digoxin and frusemide. When admitted he had uncontrolled atrial fibrillation and the E.C.G 
showed myocardial iscnaemia. Treatment with oral digoxin was continued, as was the diuretic therapy. On the third day the heart rate, previously satisfactory, was found to be $200 / \mathrm{min}$. The E.C.G. (see Fig.) showed tachycardia with alternating ventricular complexes (" bidirectional tachycardia"). Propranolol was given by mouth in a dose of $10 \mathrm{mg}$., and in 30 minutes the ventricular rate had fallen to $80 / \mathrm{min}$.; by 45 minutes it was $48 / \mathrm{min}$., with abolition of the aberrant patterns; and by two hours $30 / \mathrm{min}$. Atropine sulphate $0.5 \mathrm{mg}$. was given intravenously, this being followed by acceleration of the rate to about $80 / \mathrm{min}$. Six hours after propranolol a tendency to further slowing was still apparent, nd escape from control did not take place until more than nine hours from its administration, when a tachycardia of $150 / \mathrm{min}$. emerged, rapidly controlled by a further oral dose of $5 \mathrm{mg}$. of propranolol. The cardiac rhythm gave no further cause for concern, but the patient's general condition gradually deteriorated and he died in uraemia five days later. Permission for necropsy was not obtained,

\section{COMMENT}

The advent of $\beta$-adrenergic blockade has had a revolutionary effect on the management of digitalis-induced arrhythmias. Indeed, propranolol has been described as a specific antagonist of digitalis. Turner (1966) says simply, "Propranolol is indicated in the treatment of digitalis-induced arrhythmias." Of his 17 patients only one showed undue ventricular slowing. Dosage consisted of either $30 \mathrm{mg}$. by mouth thrice daily, or
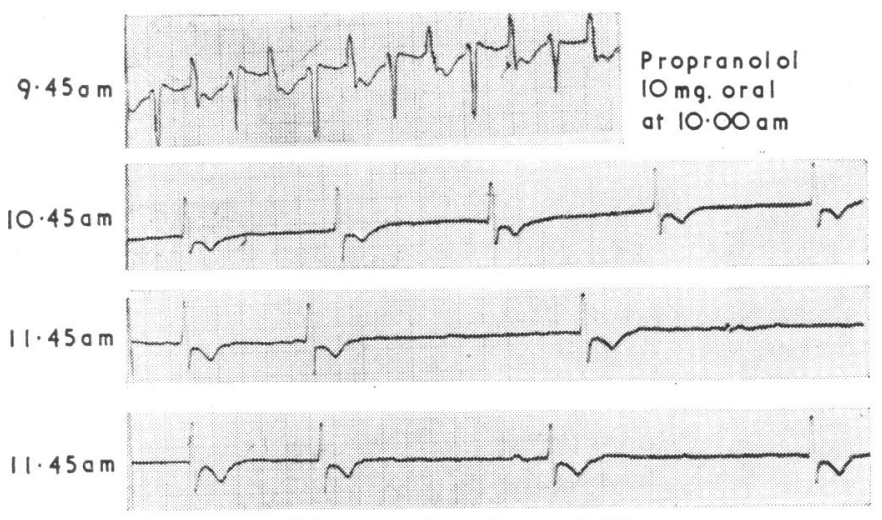
Atropine sulphote $0.5 \mathrm{mg}$. i.v. at 11.55 am
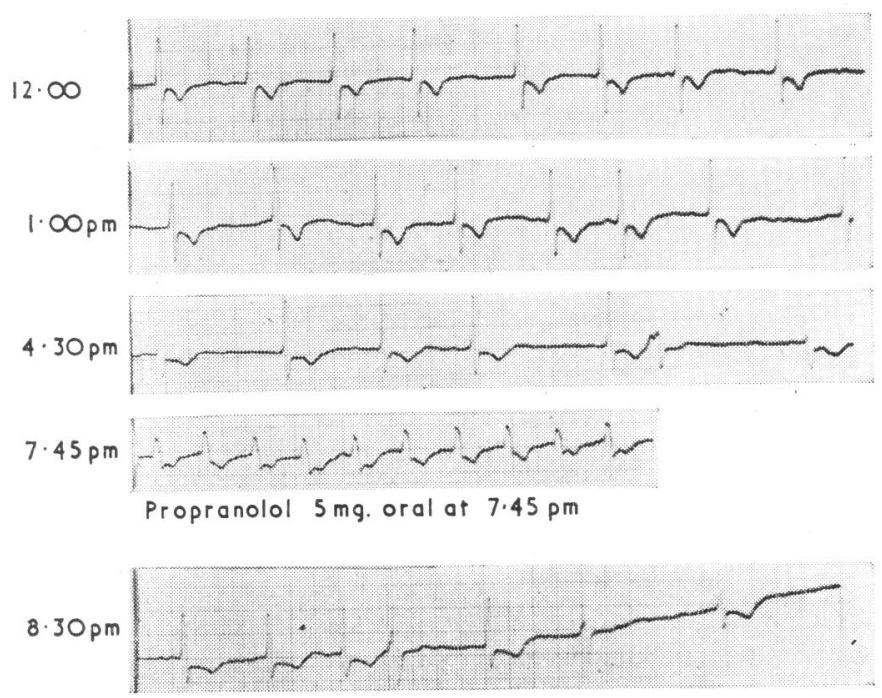

Electrocardiogram. Case 2.
5 to $10 \mathrm{mg}$. intravenously. In contrast, each of the cases described here received a single oral dose of $10 \mathrm{mg}$. and developed bradycardia within two hours.

The action of propranolol on cardiac rhythm is fourfold (Schamroth, 1966). It increases the refractory period at the sinoatrial node and at the atrioventricular junction; it depresses automaticity of the sinoatrial pacemaker and of ectopic myocardial pacemakers. Digoxin increases myocardial contractility, depresses atrioventricular conduction, and increases sensitivity of the heart rate to vagal stimulation (Friedberg, 1966). The combination of digoxin and propranolol would be expected to produce a synergistic slowing of the sinoatrial discharge rate and of atrioventricular conduction, while the antagonistic effect on ectopic pacemakers should tend to suppress digitalis-induced arrhythmias. In particular, the combination of $\beta$-sympathetic blockade and digitalis-enhanced vagal sensitivity would predispose to further fall in the heart rate.

The combined effects, then, of digitalis intoxication and propranolol overdosage would be predicted to comprise slowing of the atrial rate, increase in the degree of atrioventricular block, suppression of the ectopic rhythm, and disproportionate slowing of the ventricular rate.

The recommended oral dose of propranolol is 10 to $30 \mathrm{mg}$. three or four times daily for arrhythmias and 160 to $240 \mathrm{mg}$. daily for angina. It is not certain that the undue sensitivity to propranolol shown by these two patients is wholly attributable to digoxin intoxication. Indeed, individual idiosyncrasy must play a part. If so, then undue sensitivity is unpredictable before beginning treatment, and it would seem wise, not only in digitalis-treated patients but in all patients, to test the individual responsiveness to oral propranolol by giving a test dose of $5 \mathrm{mg}$. or less before proceeding to a full dose or to combine full dosage of propranolol with a protective dose of atropine. These precautions should be mandatory where the patient has already received digitalis.

\section{CONCLUSION}

The efficacy of propranolol in controlling arrhythmias associated with digitalis administration has been confirmed in two cases-one of frequent ventricular extrasystoles, the other of bidirectional tachycardia. The latter appears to be the first reported example of bidirectional tachycardia treated with propranolol. In both cases undue sensitivity to oral propranolol produced progressive bradycardia, and it seems reasonable to postulate a synergistic action with digitalis as a basis for this. This situation is highly dangerous, and may be lethal, but can be prevented by the use of a test dose of propranolol, or possibly by the routine administration of atropine along with the propranolol. The size of dose recommended in angina pectoris should never be given without previous observation of the effect of a small dose of propranolol. Provided these precautions are observed, the use of oral propranolol should be simple and safe.

I am grateful to Dr. J. Basil Rennie for permission to publish details of these two cases.

D. A. L. WATT, M.B., M.R.C.P., M.R.C.P.ED., M.R.C.P.GLASG., Senior Medical Registrat, Stobhill General Hospital, Glasgow N.1.

REFERENCES

Friedberg, C. K. (1966). Diseases of the Heart, 3rd ed., p. 352. Philadelphia and London.

Schamroth, L. (1966). Amer. F. Cardiol., 18, 438.

Turner, J. R. B. (1966). Amer. F. Cardiol., 18, 450. 